\title{
Ethnic differences in invasive management of coronary disease: prospective cohort study of patients undergoing angiography
}

\author{
Gene Feder, Angela M Crook, Patrick Magee, Shrilla Banerjee, Adam D Timmis, Harry Hemingway
}

\begin{abstract}
Objectives To compare rates of revascularisation in south Asian and white patients undergoing coronary angiography in relation to the appropriateness of revascularisation and clinical outcome.

Design Prospective cohort study of patients with two and a half years' follow up; appropriateness of revascularisation rated by nine experts with no knowledge of ethnicity of patient.

Setting Tertiary cardiac centre in London with referral from five contiguous health authorities. Participants Consecutive patients (502 south Asian, 2974 white) undergoing coronary angiography in the appropriateness of coronary revascularisation study (ACRE).
\end{abstract}

Main outcome measures Coronary revascularisation, non-fatal myocardial infarction, mortality.

Results There was no difference between south Asian and white patients in the proportions deemed appropriate for revascularisation (72\% (361) v 68\% (2022)) or in the proportions for whom the physician's intended management was revascularisation (39\% (196) v 41\% (1218)). Among patients appropriate for revascularisation, age adjusted rates of coronary angioplasty (hazard ratio $0.69,95 \%$ confidence interval 0.47 to $1.00, \mathrm{P}=0.058$ ) and coronary artery bypass grafting $(0.74,0.58$ to 0.91, $\mathrm{P}=0.007$ ) were lower in south Asian than in white patients. These differences were smaller but still present after adjustment for socioeconomic status and after restriction of analysis to those patients for whom the intended management was revascularisation. There were no differences in mortality and non-fatal myocardial infarction between south Asian and white patients (1.07, 0.78 to 1.47$)$.

Conclusion Among patients deemed appropriate for coronary artery bypass grafting, south Asian patients are less likely than white patients to receive it. This difference is not explained by physician bias.

\section{Introduction}

There is growing international concern that the ethnic origin of a patient may unfairly affect access to medical care such that equal treatment is not provided for equal need. ${ }^{12}$ In the United States ${ }^{3}$ and England ${ }^{4}$ coronary disease and mortality ${ }^{5}$ are more common in the largest ethnic minorities than in the white population. Some reports from the United States suggest that black and Hispanic Americans receive less invasive treatment for coronary artery disease than white people. $^{67}$

These studies leave important questions unanswered. How can we best characterise the need for treatment or ability to benefit given that few trials on invasive management of coronary disease have partici- pants from ethnic minorities? To what extent might the socioeconomic status of patients, rather than ethnicity itself, explain treatment differences? ${ }^{89}$ To what extent is the physician not offering revascularisation or the patient not taking up the offer? There have been five studies reported from England that showed differences between south Asian and white patients in the invasive management of coronary disease. ${ }^{10-14}$ Their small sample size (combined total of 476 south Asian patients) and omission of details on severity of illness, appropriateness of procedure, and other confounding factors precludes any conclusion about unfair differences between ethnic groups. There have been no prospective studies investigating ethnic differences in revascularisation in the United Kingdom that have measured clinical outcome.

We compared prospectively rates of coronary angioplasty and coronary artery bypass grafting and clinical outcomes in 502 south Asian patients and 2974 white patients who were undergoing angiography. In the appropriateness of coronary revascularisation (ACRE) study, appropriateness was measured by the ratings of a multidisciplinary panel. Such methods of rating offer important advantages for investigating potential inequity as they produce a measurement, blind to ethnicity, of the extent to which revascularisation is expected to lead to health benefits. Patients revascularised appropriately (according to these ratings) live longer than those who are not revascularised. ${ }^{15}$

\section{Methods}

Participants-Consecutive patients undergoing coronary angiography between 15 April 1996 and 14 April 1997 at the hospitals of one NHS trust were eligible for inclusion in the appropriateness of coronary revascularisation study if they lived within an area defined by five contiguous health authorities. There were no exclusion criteria, and 4121 patients were identified. The population of the health authorities was 2.833 million, and $89 \%$ of the angiographies performed on their residents were done within the trust. Ethical approval for the study was obtained from the five local research ethics committees, and written informed patient consent was sought from participants. Details of the ACRE study have been reported elsewhere. ${ }^{15}$

Clinical record data-On the day of their index coronary angiography we identified eligible patients by examination of ward admission and catheter books. Trained nurses extracted data from case notes ( $n=4020)$ using standardised forms. They collected data on clinical presentation (RAND definitions ${ }^{16}$ ); functional severity of angina (Canadian cardiovascular society); smoking; history of hypertension, diabetes, or heart failure; results of exercise electrocardiography;

\author{
Department of \\ General Practice \\ and Primary Care, \\ Barts and the \\ London, Queen \\ Mary's School of \\ Medicine and \\ Dentistry, London \\ EN1 4NS \\ Gene Feder \\ professor of primary \\ care research and \\ development \\ Department of \\ Research and \\ Development, \\ Kensington and \\ Chelsea and \\ Westminster Health \\ Authority, London \\ W2 6LX \\ Angela M Crook \\ statistician \\ Harry Hemingway \\ director of research \\ and development \\ Bart's and The \\ London NHS Trust, \\ Cardiac Directorate, \\ London E2 9JX \\ Patrick Magee \\ consultant \\ cardiothoracic \\ surgeon \\ Shrilla Banerjee \\ specialist registrar in \\ cardiology \\ Adam D Timmis \\ consultant \\ cardiologist \\ Correspondence to: \\ G Feder g.s.feder@ \\ qmul.ac.uk
}

BMJ 2002;324:511-6 
blood pressure; weight and height; admissions to hospital and visits to general practitioner, emergency departments, and outpatients in the past 12 months; time spent on waiting list; and the cardiologist's intended management (medical, coronary angioplasty, or coronary artery bypass grafting) after angiography.

Questionnaire data-On the day of their index angiography patients completed a questionnaire (3301/4020, 82\% response rate) that obtained details on their use of health services in the past year and socioeconomic status (age at leaving full time education and annual household income).

Assignment of ethnicity-We obtained self assigned ethnicity based on the 1991 census classification by questionnaire on the day of index angiography and identified 424 participants from south Asian ethnic groups. For patients with missing questionnaire data, their given and family names were cross matched on a database of 15000 names used to identify south Asian patients in routine data from east London. ${ }^{17}$ This database identified a further 78 south Asian patients. We considered this system valid because the name database is highly specific (99\%); the name assigned and self assigned methods identified similar proportions of south Asian proportions (15.6\% and 12.8\%, respectively); and confining the analyses to those with self assigned ethnicity did not affect the results. Of 502 south Asian participants, 41\% were Indian, 29\% Pakistani, 25\% Bangladeshi, and 5\% Sri Lankan. The number of participants in ethnic groups other than south Asian or white was too small for analysis.

Angiographic data-Angiographic findings were obtained from the angiogram report held in the case notes and coded blind to the clinical details. The severity of disease in each of the 27 coronary artery segments defined by the coronary artery $s t u d y^{18}$ was coded and the number of diseased vessels calculated..$^{15}$ Two cardiologists who were blinded to the clinical details examined a random subsample of coronary angiograms from 209 patients. Their assessment of the number of diseased vessels and the presence of impaired left ventricular function showed good agreement beyond chance with the assessment of the trained coder (weighted $\kappa>0.6$ ). ${ }^{19}$

Appropriateness ratings - Ratings of appropriateness for coronary angioplasty and coronary artery bypass grafting were determined in 1995 before recruitment of the cohort by a nine member expert panel using the RAND-Delphi technique. ${ }^{16}$ The validity and reliability of the ACRE ratings have been reported. ${ }^{20}$ RAND grouped specific indications into broad clinical presentations and categorised them according to severity of symptoms, number of diseased vessels, ejection fraction, exercise electrocardiogram, operative risk, and current medications. The panel considered revascularisation to be appropriate when benefits exceeded risks by a sufficient margin to make the procedure worth performing and to be of uncertain appropriateness when benefits and risks were about equal or when the best available evidence did not support a judgment either way. Ethnicity of the patients was not included in judgments about appropriateness. The panel's rating of appropriateness was assigned to each patient in the cohort; clinicians were not aware of the appropriateness ratings of their patients.
Follow up and outcomes-We identified first revascularisation procedures performed after the index coronary angiography by cross checking electronic information systems against catheter laboratory and theatre records. All patients were followed up for death or non-fatal myocardial infarction until 14 April 1999 giving a median follow up of 30 months. In total the records of $4094(99 \%)$ patients were flagged for mortality at the Office for National Statistics central registry. We ascertained potential cases of non-fatal myocardial infarction by flagging records at the

Table 1 Patient characteristics and use of health service in south Asian and white patients undergoing coronary angiography. Figures are numbers (age adjusted percentage) of patients unless otherwise stated

\begin{tabular}{lcrc} 
& $\begin{array}{c}\text { South Asians } \\
\mathbf{n}=\mathbf{5 0 2}\end{array}$ & $\begin{array}{c}\text { Whites } \\
\mathbf{n}=\mathbf{2 9 7 4}\end{array}$ & $\begin{array}{c}\mathbf{P} \\
\text { value }\end{array}$ \\
\hline Age (years): & & & \\
\hline$\leqslant 49$ & $136(27)$ & $411(14)$ & \\
\hline $50-59$ & $186(37)$ & $805(27)$ & \\
\hline $60-69$ & $152(30)$ & $1151(39)$ & \\
\hline$\geqslant 70$ & $28(6)$ & $580(20)$ & 0.001 \\
\hline Women & $111(22)$ & $862(29)$ & 0.037 \\
\hline Left full time education aged $\leqslant 16$ years & $149(32)$ & $2346(79)$ & 0.001 \\
\hline Annual household income $<£ 10400$ & $155(69)$ & $1022(53)$ & 0.001
\end{tabular}

Risk factors for coronary heart disease:

\begin{tabular}{llll}
\hline Ex-smoker (former/current) & $139(40)$ & $1604(61)$ & 0.001 \\
\hline
\end{tabular}

Smoker $37(8) \quad 319(13)$

\begin{tabular}{lccc}
\hline History of hypertension & $191(39)$ & $889(30)$ & 0.001 \\
\hline
\end{tabular}

\begin{tabular}{llll}
\hline Mean systolic blood pressure $(\mathrm{mm} \mathrm{Hg})$ & 134 & 133 & 0.70 \\
\hline Mean total cholesterol:HDL ratio & 5.64 & 5.34 & 0.002
\end{tabular}

\begin{tabular}{llll}
\hline Mean triglycerides $(\mathrm{mmo} / \mathrm{l})$ & 2.15 & 1.75 & 0.001 \\
\hline
\end{tabular}

\begin{tabular}{lcrr}
\hline Diabetes & $156(33)$ & $288(9)$ & 0.001 \\
\hline
\end{tabular}

\begin{tabular}{llll}
\hline Mean body mass index $>27 \mathrm{~kg} / \mathrm{m}^{2}$ & 32 & 51 & 0.001
\end{tabular}

Clinical presentation:

\begin{tabular}{llll}
\hline Chronic stable angina class I/II & $169(34)$ & $1041(35)$ & 0.35 \\
\hline
\end{tabular}

\begin{tabular}{llll}
\hline Chronic stable angina class III/IV & $201(44)$ & $1077(35)$ & $0.014^{*}$
\end{tabular}

\begin{tabular}{llll}
\hline Unstable angina (past 3 months) & $88(19)$ & $425(14)$ & 0.056
\end{tabular}

\begin{tabular}{llll}
\hline Myocardial infarction (past 3 months) & $62(12)$ & $375(13)$ & 0.44
\end{tabular}

Previous investigation:

\begin{tabular}{lccl}
\hline Lipids estimation & $339(68)$ & $2056(69)$ & 0.36 \\
\hline Exercise ECG & $234(44)$ & $1438(49)$ & 0.035 \\
\hline $\begin{array}{l}24 \text { hour ECG or echocardiograhy or } \\
\text { thallium scan }\end{array}$ & $81(18)$ & $608(20)$ & 0.26 \\
\hline
\end{tabular}

\begin{tabular}{llll}
\hline Coronary angiography & $139(28)$ & $757(25)$ & 0.12
\end{tabular}

Current medication:

\begin{tabular}{lrrl} 
Current medication: & & & \\
\hline Aspirin & $379(75)$ & $2213(75)$ & 0.69 \\
\hline$\beta$ blockers & $227(42)$ & $1290(44)$ & 0.52 \\
\hline Statins & $75(14)$ & $605(21)$ & 0.001 \\
\hline $\begin{array}{l}\text { Angiotensin converting enzyme } \\
\text { inhibitors }\end{array}$ & $117(25)$ & $659(22)$ & 0.33 \\
\hline
\end{tabular}

\begin{tabular}{llll}
\hline Calcium antagonists & $235(52)$ & $1405(47)$ & 0.30
\end{tabular}

\begin{tabular}{llll}
\hline Nitrates & $274(58)$ & $1775(59)$ & 0.18
\end{tabular}

Angiographic findings:

\begin{tabular}{llll}
\hline No significant disease & $153(26)$ & $776(28)$ & 0.74
\end{tabular}

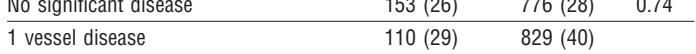

2 vessel disease $105(29) \quad 634(29)$

\begin{tabular}{llll}
\hline 3 vessel disease/left main stem & $130(42)$ & $704(31)$ & $0.001 \dagger$ \\
\hline
\end{tabular}

Diffuse disease $70(18) \quad 318(11) \quad 0.001$

\begin{tabular}{llll}
\hline Impaired left ventricular function & $98(26)$ & $562(23)$ & 0.91
\end{tabular}

\begin{tabular}{llll}
\hline Median (interquartile range) wait for & $63(19-167)$ & $61(14-162)$ & 0.45
\end{tabular} angiogram (days)

Median (interquartile range) No of uses of health service in past year:

\begin{tabular}{llll}
\hline General practitioner visits & $4(2-11)$ & $3(1-6)$ & 0.001
\end{tabular}

\begin{tabular}{llll}
\hline Outpatient consultations & $2(1-3)$ & $1(0-1)$ & 0.63
\end{tabular}

\begin{tabular}{llll}
\hline Hospital admissions & $2(1-3)$ & $1(0-1)$ & 0.63 \\
\hline
\end{tabular}

\begin{tabular}{llll}
\hline Emergency department attendances & $1(0-1)$ & $1(0-1)$ & 0.10
\end{tabular}

${ }^{*}$ Compared with mild angina or no angina.

tComparing severity of disease in those with coronary artery disease. 
clearing system for discharges coded for coronary artery disease using the unique NHS number. We further checked the completeness of these data by manually searching admission records in 13 referring hospitals.

Statistical analysis-We compared rates of revascularisation, mortality, and non-fatal myocardial infarction between south Asian and white patients with age adjusted hazard ratios and their 95\% confidence intervals. Hazard ratios less than one indicate that south Asian patients had a lower rate of revascularisation or mortality than white patients. Analyses are presented according to clinical need and category of appropriateness. We used Cox's proportional hazards models to adjust for the effects of socioeconomic status. Times to revascularisation were compared between groups by Kaplan-Meier curves and the log rank test. All analyses were performed in SAS.

\section{Results}

There were demographic and clinical differences between the two groups of participants (table 1). Compared with white patients south Asian patients tended to be younger, male, non-obese, non-smokers, and more educated with lower household incomes. Diabetes, adverse lipoprotein profile, severe angina or atypical chest pain, and triple vessel or left main stem disease detected on angiography were also more common in south Asian patients. A lower proportion had undergone exercise stress testing. There were no significant differences between the two ethnic groups in clinical presentation, previous investigations, and interventions. South Asian patients had more visits to their general practitioner in the year before angiography than white patients but did not spend longer on the waiting list for angiography.

The prospective clinical validity of our appropriateness ratings, previously shown in the whole cohort, was also found among south Asians. In south Asian patients thought appropriate for coronary artery bypass grafting, the age adjusted hazard ratio for mortality (patients who did not receive it versus those who did) was 1.99 (95\% confidence interval 0.65 to 6.07$)$.

Figure 1 shows that the overall rate of revascularisation was lower among south Asian patients than white patients (log rank $\mathrm{P}=0.017)$; the curves diverged after the first two months. Table 2 shows that the overall rate

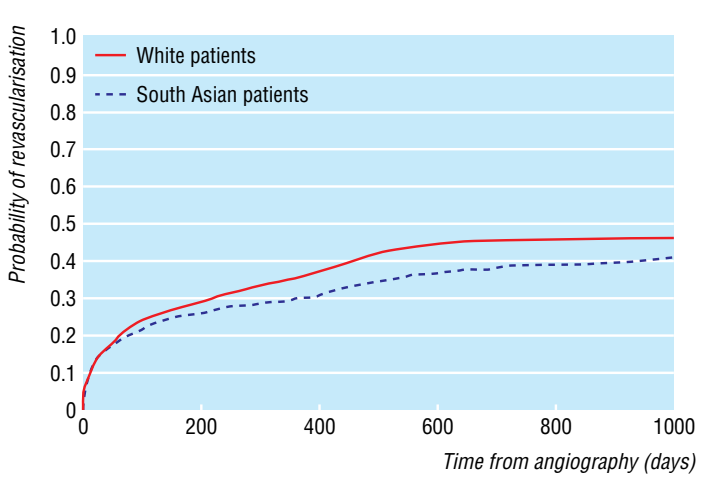

Fig 1 Probability of any revascularisation in south Asian and white patients after angiography among all patients

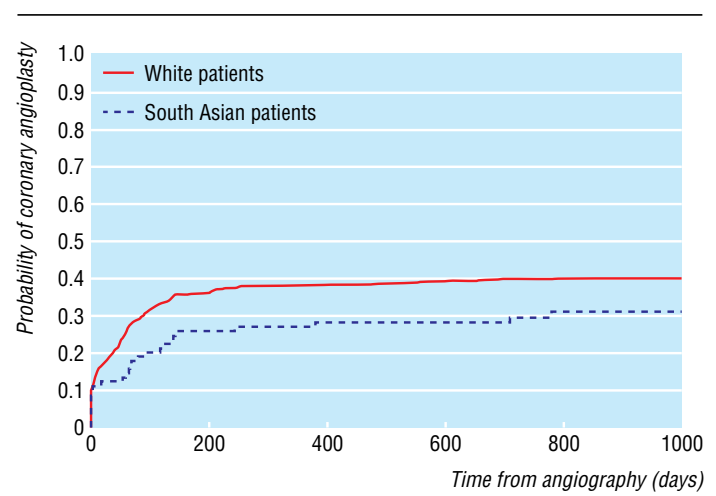

Fig 2 Probability of south Asian and white patients receiving coronary angioplasty after angiography among those deemed appropriate for angioplasty

adjusted for age was lower in south Asian patients. This lower rate tended to be consistent within groups of clinical need, with hazard ratios less than unity and $\mathrm{P}<0.05$ within groups aged over 58 years and those with severe angina, positive result on exercise electrocardiography, and triple vessel disease.

There was no difference between south Asian and white patients in the proportions that were rated by the panel as appropriate for revascularisation $(72 \% v 68 \%)$. Among patients deemed appropriate for angioplasty, however, south Asian patients were less likely to receive it than white patients (log rank $\mathrm{P}=0.082$ (fig 2), age adjusted hazard ratio $0.69,95 \%$ confidence interval 0.47 to $1.00, \mathrm{P}=0.058)$. The age adjusted hazard ratio was 0.23 ( 0.07 to $0.72, \mathrm{P}=0.01)$ for Bangladeshis, 0.34 (0.12 to $0.90, \mathrm{P}=0.03$ ) for Pakistanis, and 1.22 ( 0.78 to $1.91, \mathrm{P}=0.37$ ) for Indians. Of all patients undergoing

Table 2 Age adjusted hazard ratios for any revascularisation in south Asian and white patients, within categories of clinical need in patients with coronary artery disease

\begin{tabular}{|c|c|c|c|c|}
\hline & $\begin{array}{l}\text { South Asian } \\
(\mathrm{n}=345)\end{array}$ & $\begin{array}{c}\text { White } \\
\text { (n=2167) }\end{array}$ & $\begin{array}{c}\text { Hazard ratio } \\
(95 \% \mathrm{Cl})\end{array}$ & $\begin{array}{c}P \\
\text { value }\end{array}$ \\
\hline All patients with coronary artery disease & $191(55)$ & $1308(60)$ & $0.88(0.75$ to 1.02$)$ & 0.09 \\
\hline \multicolumn{5}{|l|}{ Age (years): } \\
\hline$<58$ & $99(60)$ & $392(60)$ & $0.99(0.79$ to 1.24$)$ & 0.94 \\
\hline$\geqslant 58$ & $92(51)$ & $916(61)$ & 0.79 (0.64 to 0.97$)$ & 0.03 \\
\hline \multicolumn{5}{|l|}{ Sex: } \\
\hline Female & $26(50)$ & $290(62)$ & 0.68 (0.47 to 1.05$)$ & 0.09 \\
\hline Male & $165(56)$ & $1015(60)$ & $0.92(0.77$ to 1.08$)$ & 0.29 \\
\hline \multicolumn{5}{|l|}{ Age at leaving school (years): } \\
\hline$\leqslant 16$ & $53(54)$ & $1038(60)$ & $0.83(0.63$ to 1.10$)$ & 0.20 \\
\hline$>16$ & $82(59)$ & $153(59)$ & 0.91 (0.69 to 1.19$)$ & 0.47 \\
\hline \multicolumn{5}{|l|}{ Income } \\
\hline$<£ 10400$ & $58(52)$ & $441(57)$ & 0.86 (0.65 to 1.13$)$ & 0.28 \\
\hline$>£ 10400$ & $40(63)$ & $391(60)$ & $1.02(0.74$ to 1.43$)$ & 0.88 \\
\hline \multicolumn{5}{|l|}{ Severity of angina: } \\
\hline Class I/II & $62(52)$ & $480(61)$ & $0.78(0.60$ to 1.01$)$ & 0.06 \\
\hline Class III/IV & $92(60)$ & $600(69)$ & $0.76(0.62$ to 0.96$)$ & 0.02 \\
\hline \multicolumn{5}{|l|}{ Exercise ECG: } \\
\hline Not done & $106(59)$ & $672(62)$ & $0.92(0.74$ to 1.13$)$ & 0.41 \\
\hline Abnormal & $61(53)$ & $470(62)$ & $0.76(0.58$ to 0.99$)$ & 0.05 \\
\hline \multicolumn{5}{|l|}{ No of diseased vessels: } \\
\hline 1 & $61(55)$ & $432(52)$ & 1.04 (0.79 to 1.35$)$ & 0.82 \\
\hline 2 & $61(58)$ & $396(62)$ & 0.93 (0.68 to 1.19$)$ & 0.47 \\
\hline 3/left main stem & $69(53)$ & $480(68)$ & $0.66(0.51$ to 0.86$)$ & $<0.01$ \\
\hline Diffuse & $33(47)$ & $191(61)$ & 0.73 (0.50 to 1.06$)$ & 0.10 \\
\hline Impaired left ventricular function & $49(55)$ & $263(52)$ & 1.05 (0.77 to 1.43$)$ & 0.77 \\
\hline Diabetes & $69(54)$ & $136(57)$ & $0.92(0.68$ to 1.23$)$ & 0.56 \\
\hline
\end{tabular}




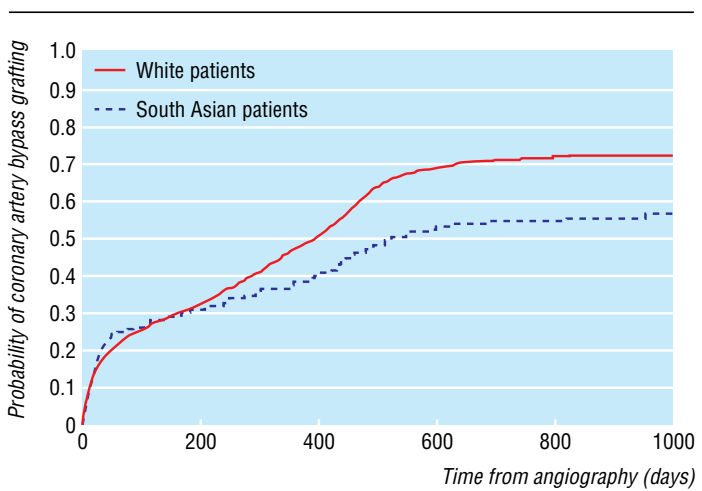

Fig 3 Probability of south Asian and white patients receiving coronary artery bypass graft after angiography among those deemed appropriate for coronary artery bypass graft

angioplasty, stents were placed in $51 \%$ of south Asian patients and $56 \%$ of white patients $(\mathrm{P}=0.479)$.

Among patients deemed appropriate for coronary artery bypass grafting, south Asian patients were less likely to receive it than white patients $(\log$ rank $\mathrm{P}=0.002$ (fig 3), age adjusted hazard ratio $0.74,0.58$ to 0.91 , $\mathrm{P}=0.007)$. The age adjusted hazards ratio was $0.56(0.37$ to $0.84, \mathrm{P}=0.006)$ for Bangladeshis, 0.78 (0.52 to 1.18 ; $\mathrm{P}=0.24$ ) for Pakistanis, and 0.89 (0.64 to $1.23, \mathrm{P}=0.48$ ) for Indians. Figure 2 shows that the lower rate of angioplasty among south Asian patients compared with white patients became evident within the first month. Figure 3 shows that for coronary artery bypass grafting the curves diverged after six months. The difference between south Asian patients and white patients in rates of coronary artery bypass grafts was attenuated by adjustment for education $(0.80,0.59$ to $1.08)$, income $(0.88,0.65$ to 1.20$)$, and education and income combined $(0.81,0.60$ to 1.16$)$.

There was no difference between south Asian patients and white patients in the proportion for whom the cardiologists' intended management after angiography was revascularisation (128 (39\%) v 836 $(41 \%))$. South Asian patients for whom angioplasty was intended had a lower rate for this procedure rate than white patients $(0.71,0.52$ to $0.98, \mathrm{P}=0.034)$. South Asian patients for whom coronary artery bypass grafting was intended also had a lower rate for this procedure than white patients $(0.79,0.60$ to $1.04, \mathrm{P}=0.093)$.

Figure 4 shows that there were no differences in mortality between the groups of patients with coronary artery disease (age adjusted hazard ratio 1.05, 0.68 to

\begin{tabular}{|c|c|c|c|c|c|c|}
\hline & \multicolumn{6}{|c|}{$\begin{array}{l}\text { No }(\%) \text { of deaths and non- } \\
\text { fatal myocardial infarction }\end{array}$} \\
\hline & $\begin{array}{l}\text { South } \\
\text { Asians } \\
(\mathrm{n}=502)\end{array}$ & $\begin{array}{l}\text { Whites } \\
(n=2974)\end{array}$ & $\begin{array}{l}\text { Hazard ratio } \\
(95 \% \mathrm{CI})\end{array}$ & $P$ value & $\begin{array}{r}\text { Favours } \\
\text { south Asian } \\
\text { patients }\end{array}$ & $\begin{array}{l}\text { Favours } \\
\text { white } \\
\text { patients }\end{array}$ \\
\hline All patients & $50(10)$ & $386(13)$ & $0.96(0.71$ to 1.29$)$ & 0.78 & & - \\
\hline Patients with coronary disease & $45(13)$ & $312(14)$ & 1.07 (0.78 to 1.47$)$ & 0.68 & & \\
\hline \multicolumn{7}{|l|}{ Treatment } \\
\hline Medical & $23(15)$ & $148(17)$ & 1.04 (0.66 to 1.60$)$ & 0.90 & & \\
\hline Coronary angioplasty & $6(8)$ & $63(13)$ & $0.63(0.27$ to 1.47$)$ & 0.29 & & 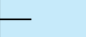 \\
\hline \multirow[t]{2}{*}{ Coronary artery bypass graft } & $16(13)$ & $101(12)$ & 1.38 (0.80 to 2.38$)$ & 0.25 & & \\
\hline & & & & 0. & 0.5 & 02.03. \\
\hline
\end{tabular}

Fig 4 Age adjusted hazard ratios for death and non-fatal myocardial infarction at 2.5 year follow up for south Asian with white patients
1.63) nor in rates of combined death and non-fatal myocardial infarction (1.07, 0.78 to 1.47$)$.

\section{Discussion}

In a prospective population based study of consecutive patients undergoing angiography, south Asian patients were less likely than white patients to undergo subsequent coronary revascularisation. These differences were independent of differences in clinical need between the groups as rated by a panel of experts and were not wholly explained by the differences in socioeconomic status. Physician bias in recommending patients for revascularisation did not account for these findings, suggesting the importance of patients' understanding and preferences. As all patients in our cohort had been referred for angiography we cannot exclude clinician bias before this investigation.

Our study has several advantages over previous research. The appropriateness of the coronary revascularisation study, of which this study was a part, is uniquely able to characterise the clinical need of patients by using ratings of appropriateness as assessed by an expert panel that have been validated against clinical outcomes. ${ }^{15}$ Patients who are considered appropriate for revascularisation but who do not receive it are less likely to survive and more likely to have angina than those who are revascularised. Our findings are consistent with some ${ }^{7}$ but not all $^{21}$ results of US studies that investigated rates of cardiovascular procedures in black and white patients after appropriateness of interventions was accounted for.

Another advantage of our study was the opportunity to investigate whether ethnic differences in coronary revascularisation can be explained by socioeconomic status. Ecological studies in the United Kingdom (which did not take ethnicity into account) have shown an association between economic deprivation and lower rates of revascularisation, ${ }^{22}$ echoing similar findings in the United States. ${ }^{23}$ In general, the south Asian participants in our study had lower incomes, though they were more educated than white participants. Adjustment for education and income attenuated, but did not abolish, the difference in rate of coronary artery bypass grafting between the two groups. The differences in rates of revascularisation between south Asian and white patients was largest for patients of Bangladeshi origin. The difference tended to be greater among older patients, women, and those of lower socioeconomic status. The results of these subgroup analyses suggest that cultural differences and language barriers may be responsible.

The third advantage over previous studies is our comparison of intended management recorded by the cardiologist at the time of angiography with actual revascularisation status on follow up. Revascularisation was the intended management in similar proportions of participants, but south Asian patients underwent fewer procedures. Schulman et al used hypothetical case scenarios and suggested that clinicians' recommendations for angiography may be biased by the ethnicity of the patient. ${ }^{24}$ Our findings, based on real patients and real decisions, do not support their results. In a study in New York, Barnhart et al analysed treatment recommendations after angiography in 180 patients with severe coronary artery disease. They 
found that Hispanic patients were less likely to be recommended for revascularisation than white patients but did not compare recommendations with actual procedures. $^{25}$

\section{Why are revascularisation rates lower in south Asian patients?}

South Asian and white patients may differ in their understanding of the risks and benefits of revascularisation. The administrative system, through which revascularisation is provided, involves written communication in English, long waiting lists, and repeated outpatient assessments. Even if communication is not a barrier, ethnic groups may differ in willingness to undergo revascularisation. Studies from the United States have shown that black and white patients have different preferences for treatment. ${ }^{26}$ We did not collect data on refusal of revascularisation. Until the impact of ethnicity on the values (utilities) patients place on the outcomes of revascularisation has been investigated, we cannot conclude that the differences we observed are unfair. The observation that ethnic differences in the rate of revascularisation arose once patients had been put on the waiting list, rather than earlier on, is more consistent with differences in the ability or willingness to negotiate the system rather than explicit refusal to have the procedure. Deaths on the waiting list cannot explain our findings as only one south Asian patient died before he received an intended revascularisation.

Ethnic differences in rates of revascularisation were not associated with differences in mortality and non-fatal myocardial infarction, though the confidence intervals were wide. To detect a 30\% excess mortality (with $80 \%$ power, $\mathrm{P}<0.05$ ) in south Asian patients compared with white patients we would need to follow up 2000 south Asian patients for 2.5 years. This would be a large proportion of the total number of south Asian patients undergoing coronary angiography in the United Kingdom.

The NHS, predicated on fair access to treatment, has no mechanism to monitor ethnic differences in the invasive management of coronary disease in relation to patient characteristics and clinical outcome. Until such information systems are available nationally, ${ }^{27}$ it will be difficult to investigate systematically any differences in treatment between patients of Indian, Pakistani, and Bangladeshi origin and to explore possible interactions with age, sex, and social position. The absence of a comprehensive system to collect data on ethnicity from primary to tertiary care prevents investigation of inequity in the management of all conditions, not just coronary disease.

South Asians had more consultations with a general practitioner in the year before angiography and more severe angina and coronary artery disease than white patients. These findings are compatible with a higher threshold for cardiac referral of south Asian patients from general practice and require further investigation. Shaukat et al found that the interval between onset of symptoms and attendance at a cardiology clinic was longer for south Asian patients, ${ }^{11}$ while Chaturvedi found that south Asian patients had a lower threshold for seeking medical attention when they had symptoms of angina. ${ }^{28}$

\section{What is already known on this topic}

US studies have shown inequity in use of cardiac revascularisation procedures between white patients and African-Americans

Studies in England comparing revascularisation in white and south Asian patients have been too small for conclusive results and have not considered appropriateness of treatment

\section{What this study adds}

Rates of coronary revascularisation among comparable patients with coronary artery disease are lower among south Asian patients than white patients

Physician bias did not explain these differences nor did socioeconomic status of patients

The differences in treatment did not result in large differences in clinical outcome

Our findings provide the strongest evidence to date that coronary revascularisation among comparable patients with coronary disease is less likely to be carried out in south Asian patients than in white patients in the United Kingdom. This difference can not be explained by physician bias. Proving that these differences are unfair requires much larger studies to investigate the impact on clinical outcome as well as the measurement of patient preferences. The national service framework for coronary heart disease in England and Wales explicitly requires the equitable provision of revascularisation between ethnic groups; this may not be happening.

We gratefully acknowledge the patients who participated in the study; and Rex Dawson, Alan Wood, Sue Philpott, Julie Sanders, and members of the Kensington Chelsea and Westminster research and development department for study conduct and critical comments.

Contributors: GF wrote the first draft of the paper and incorporated coauthor's comments. AMC carried out all the statistical analyses. $\mathrm{ADT}$ and $\mathrm{HH}$ are principal investigators of the ACRE study. HH was responsible for inception and design of the ACRE study. All coauthors participated in the design of the analysis and the interpretation of the data reported here and commented on drafts of the paper. GF and $\mathrm{HH}$ are guarantors.

Funding: The ACRE study was established with a grant for East London and City Health Authority and subsequently funded by a consortium of health authorities (North Essex, Barking and Havering, Redbridge and Waltham Forest), North Thames NHS research and development programme (RFG 258), British Heart Foundation (PG/97216), and Guidant and Boston Scientific Corporation. HH is supported by a national public health career scientist award from the Department of Health.

Conflict of interest: None declared.

1 Trevino FM. Quality of health care for ethnic/racial minority populations. Ethn Health 1999;4:153-64.

2 Acheson D. Independent inquiry into inequalities in health report. London: Stationery Office, 1998.

3 Fang J, Madhavan S, Alderman MH. The association between birthplace and mortality from cardiovascular causes among black and white residents of New York City. N Engl J Med 1996;335:1545-51.

4 Erens B, Primatesta P, Prior G. Health survey for England: the health of minority ethnic groups 1999. London: Stationery Office, 2001.

5 Wild S, Mckeigue P. Cross sectional analysis of mortality by country of birth in England and Wales, 1970-92. BMJ 1997;314:705.

6 Kravitz RL. Ethnic differences in use of cardiovascular procedures: new insights and new challenges. Ann Intern Med 1999;130:231-3.

7 Sheifer SE, Escarce JJ, Schulman KA. Race and sex differences in the management of coronary artery disease. Am Heart J 2000;139:848-57

8 Alter DA, Naylor CD, Austin P, Tu JV. Effects of socioeconomic status on access to invasive cardiac procedures and on mortality after acute myocardial infarction. N Engl J Med 1999;341:1359-67. 
9 Morrison C, Woodward M, Leslie W, Tunstall-Pedoe H. Effect of socioeconomic group on incidence of, management of, and survival after myocardial infarction and coronary death: analysis of community coronary event register. $B M J$ 1997:314:541.

10 Lowry PJ, Glover DR, Mace PJ, Littler WA. Coronary artery disease in Asians in Birmingham. Br Heart J 1984;52:610-3.

11 Shaukat N, de Bono DP, Cruickshank JK. Clinical features, risk factors, and referral delay in British patients of Indian and European origin with angina matched for age and extent of coronary atheroma. BMJ 1993;307:717-8.

12 Dhawan J, Bray CL. Angiographic comparison of coronary artery disease between Asians and Caucasians. Postgr Med J 1994;70:625-30.

13 Mukhtar HLW, Littler WA. Survival after myocardial infarction in Asian and white patients in Birmingham. Br Heart J 1995;73:122-4.

14 Goldsmith I, Lip GY, Tsang G, Patel RL. Comparison of primary coronary artery bypass surgery in a British Indo-Asian and white Caucasian population. Eur Heart J 1999;20:1094-100.

15 Hemingway H, Crook AM, Feder G, Banerjee S, Dawson JR, Magee P, et al. Underuse of coronary revascularization procedures in patients considered appropriate candidates for revascularization. $N$ Engl J Med 2001;344:645-54.

16 Bernstein SJ, Laouri M, Hilbourne LH, Leape LL, Kahan JO, Park RE, et al. Coronary angiography: a literature review and ratings of appropriateness and necessity. Santa Monica, CA: RAND, 1992

17 Naish J, Sturdy K, Bobby J, Pereira F. The association between Asian ethnicity and prescribing rates in east London general practices: a database study. Health Informatics Journal 1997;3:100-5.

18 Ringqvist I, Fisher LD, Mock M, Davis KB, Wedel $\mathrm{H}$, Chaitman BR, et al. Prognostic value of angiographic indices of coronary artery disease from the coronary artery surgery study (CASS). J Clin Invest 1983;71:1854-66.
19 Banerjee S, Crook AM, Dawson JR, Timmis AD, Hemingway $\mathrm{H}$ Magnitude and consequences of error in coronary angiography interpretation (the ACRE) study. Am J Cardiol 2000;85:309-14.

20 Hemingway H, Crook AM, Dawson JR, Edelman J, Edmondson S, Feder $\mathrm{G}$, et al. Rating the appropriateness of coronary artery bypass grafting: the ACRE study. J Public Health Med 1999;21:421-9.

21 Peniston RL, Lu DY, Papademetriou V, Fletcher RD. Severity of coronary artery disease in black and white male veterans and likelihood of revascularization. Am Heart J 2000;139:840-7.

22 MacLeod MC, Finlayson AR, Pell JP, Findlay IN. Geographic, demographic, and socioeconomic variations in the investigation and management of coronary heart disease in Scotland. Heart 1999;81:252-6.

23 Carlisle DM, Leake BD. Differences in the effect of patients' socioeconomic status on the use of invasive cardiovascular procedures across health insurance categories. Am J Public Health 1998;88:1089-92.

24 Schulman KA, Berlin JA, Harless W, Kerner JF, Sistrunk S, Gersh BJ, et al. The effect of race and sex on physicians' recommendations for cardia catheterization. N Engl J Med 1999;340:618-26.

25 Barnhart JM, Wassertheil-Smoller S, Monrad ES. Clinical and nonclinical correlates of racial and ethnic differences in recommendation patterns for revascularization. Clin Cardiol 2000:23:580-6.

26 Whittle J, Conigliaro J, Good CB, Joswiak M. Do patient preferences contribute to racial differences in cardiovascular procedure use? J Gen Intern Med 1997;12:267-73.

27 Aspinall PJ. The mandatory collection of data on ethnic group of inpatients: experience of NHS trusts in England in the first reporting years. Public Health 2000;114:254-9.

28 Chaturvedi N, Rai H, Ben-Shlomo Y. Lay diagnosis and health-careseeking behaviour for chest pain in south Asians and Europeans. Lancet 1997;350:1578-83.

(Accepted 4 October 2001)
ELPS

The full version of this article appears on bmj.com

\title{
Eliciting views of patients with head and neck cancer and carers on professionally derived standards for care
}

\author{
M Birchall, A Richardson, L Lee on behalf of South and West Regional Cancer Organisation \\ Tumour Panel for Head and Neck Cancer
}

Division of Surgery, University of Bristol, Bristol BS10 5NB

M Birchall reader in head and neck surgery

Research and Consultancy, London NW3 4DA

A Richardson independent research consultant

Horfield Practice, Horfield, Bristol BS7 9RR

L Lee

general practitioner

Correspondence to: M Birchall

Martin.Birchall@

Bristol.ac.uk

BMJ 2002;324:516-9

\begin{abstract}
Objectives To examine views of patients and carers on the process of care for people with head and neck cancer; to assess whether focus groups are useful in this setting; to compare priorities and standards identified with those published by healthcare professionals; and to incorporate the expressed views into existing national standards.

Design Multicentre study of nine regional focus groups.

Setting Area covered by two regional health authorities.
\end{abstract}

Participants 40 patients who had had head and neck cancer and 18 carers.

Main outcome measures Views of individuals and groups on standards. Applicability of the method for patients whose appearance and ability to communicate was altered and for recently bereaved carers. Ease of incorporation of views into national and regional standards.

Results Patients and carers participated in discussions on all the principal questions. Opinions were expressed on waiting times, information available to patients, coordination of care, and crisis management. Professionally derived standards were substantially improved by the incorporation of the views of patients and carers. There were no technical problems in carrying out this study on patients with communication difficulties or altered appearance nor with recently bereaved carers. Occasionally, participants said that the meetings were therapeutic.
Conclusions Professionally facilitated and analysed focus groups are effective in assessing views of patients with cancer and carers on professionally derived standards for care and can be applied in settings traditionally viewed as difficult. Views expressed by patients and carers are powerful motivators for change in the delivery of cancer care.

\section{Introduction}

The Calman-Hine report recommended that planning in cancer services should take account of the "views and preferences of patients." ${ }^{1}$ This requires research to ascertain what patients want and development of measures to ensure that these views are then reflected in practice. Initial national guidelines for care of patients with head and neck cancer did not take account of views of patients or carers. ${ }^{2}$ We carried out a study of focus groups with patients with head and neck cancer and carers to consider specific standards for their care. We subsequently incorporated their views into new national guidelines. ${ }^{3}$

\section{Methods}

The study took place across the South and West region. We obtained patients' names from the ten consultants who formed part of the regional tumour panel, all of whom gave at least some information on relevant patients $(n=290)$. We contacted general practitioners as needed to check that the patients were still alive. For carers we considered only spouses (or partners living 